Article

\title{
Physicochemical Properties, Antioxidant and Antidiabetic Activities of Polysaccharides from Quinoa (Chenopodium quinoa Willd.) Seeds
}

\author{
Minghui Tan ${ }^{1,2}{ }^{-}$, Senlin Chang ${ }^{1,2}$, Jianing Liu ${ }^{1}$, Hang Li ${ }^{1,2}$, Pengwei $\mathrm{Xu}^{1,2}$, Peidong Wang ${ }^{1,2}$, \\ Xiaodong Wang ${ }^{1}$, Mingxia Zhao ${ }^{1}$, Bing Zhao ${ }^{1}$, Liwei Wang ${ }^{1, *}$ and Qingsheng Zhao ${ }^{1, *(D)}$ \\ 1 Division of Bioresources and Health Product Engineering, State Key Laboratory of Biochemical Engineering, \\ Institute of Process Engineering, Chinese Academy of Sciences, Beijing 100190, China; \\ mhtan@ipe.ac.cn (M.T.); changsenlin14@mails.ucas.edu.cn (S.C.); liujianing17@mails.ucas.edu.cn (J.L.); \\ lihang18@mails.ucas.edu.cn (H.L.); xupengwei17@mails.ucas.edu.cn (P.X.); \\ wangpeidong19@mails.ucas.ac.cn (P.W.); xdwang@ipe.ac.cn (X.W.); mxzhao@ipe.ac.cn (M.Z.); \\ bzhao@ipe.ac.cn (B.Z.) \\ 2 School of Chemical Engineering, University of Chinese Academy of Sciences, Beijing 100049, China \\ * Correspondence: lwwang@ipe.ac.cn (L.W.); qszhao@ipe.ac.cn (Q.Z.); Tel./Fax: +86-010-62574372 (Q.Z.)
}

Received: 28 July 2020; Accepted: 21 August 2020; Published: 24 August 2020

\begin{abstract}
Quinoa is known for its rich nutrients and bioactive compounds. In order to elucidate the preliminary structural characteristics and biological activity of polysaccharides from quinoa (QPs), five crude polysaccharides (QPE50, QPE60, QPE70, QPE80 and QPE90) were successively fractionated by gradient ethanol, and their physicochemical properties, antioxidant and antidiabetic activities were analyzed. The results implied that their total sugar contents were 52.82\%, 63.69\%, $67.15 \%, 44.56 \%$, and $41.01 \%$, and their weight-average molecular weights were 13,785 Da, $6489 \mathrm{Da}$, $4732 \mathrm{Da}, 3318 \mathrm{Da}$, and $1960 \mathrm{Da}$, respectively. Glucose was a predominantly monosaccharide in these QPs, which together in QPE50, QPE60, QPE70, QPE80, and QPE90, respectively, made up 94.37\%, $87.92 \%, 92.21 \%, 100 \%$, and $100 \%$ of the total polysaccharide. Congo red test showed that all five QPs contained triple-helix structure. The Fourier transform-infrared spectroscopy (FT-IR) and X-ray diffractometry (XRD) results suggest that the QPs form a semi-crystalline polymer constituted typical functional groups of polysaccharide including $\mathrm{CO}, \mathrm{CH}$ and $\mathrm{OH}$. The thermogravimetric analysis (TGA) of QPs showed that weight loss was at about $200^{\circ} \mathrm{C}$ and $320^{\circ} \mathrm{C}$. The observation from scanning electron microscope (SEM) and atomic force microscope (AFM) image indicated that the morphology of QPs exhibited spherical shape. Antioxidant and antidiabetic assay exhibited that all five QPs samples had certain antioxidant and antidiabetic activities, and QPE90 showed the best antioxidant and antidiabetic activity. Overall, QPs present a promising natural source of food antioxidants and antidiabetic agents.
\end{abstract}

Keywords: Chenopodium quinoa Willd; polysaccharide; fractional precipitation; antioxidant; antidiabetic

\section{Introduction}

Quinoa, is a crop native to the Andean region. It is an annual dicotyledonous herb belonging to the genus Chenopodium, which has been cultivated for 5000-7000 years [1]. The seeds are in the shape of oval pills, and the colors are purple, red, yellow or green. The seed coat is covered with a layer of water-soluble saponins [2], so it has a slightly bitter taste. Quinoa originated in the Andean region of South America and currently grown in Bolivia, Peru, United States, Ecuador and Canada as a food crop [3]. Quinoa is rich in protein, carotenoids and Vitamin C. Its protein has a balanced composition of amino acids, with a high content of lysine (5.1-6.4\%) and methionine (0.4-1.0\%) [4]. The seed is also rich 
in mineral nutrients, such as $\mathrm{Ca}, \mathrm{Fe}, \mathrm{Zn}, \mathrm{Cu}$ and $\mathrm{Mn}$. Among them, the content of $\mathrm{Ca}(874 \mathrm{mg} / \mathrm{kg})$ and Fe $(81 \mathrm{mg} / \mathrm{kg})$ is significantly higher than that of most common cereals [5]. Therefore, quinoa is called "nutritional gold", "super grain" and "future food" by international nutritionists [6]. Quinoa has starch polysaccharides and non-starch polysaccharides. Starch is the predominant carbohydrate in quinoa seeds with a content of 58.1-64.2\%. It is composed of amylose and amylopectin. The amylopectin content is higher, accounting for $93-94 \%$ of the total starch content [7]. Non-starch polysaccharide contains cellulose, hemicellulose and pectin mainly. As a class of non-starch polysaccharides, dietary fiber is rich in quinoa, accounting for 7-9.7\%, of which insoluble dietary fiber accounts for $78 \%$. Insoluble fiber from quinoa is mainly composed of galacturonic acid, galactose, xylose and glucose, while soluble fiber is mainly composed of glucose, galacturonic acid and arabinose [8].

Polysaccharide is a kind of polymer composed of more than 10 monosaccharides connected together by different types of glycosidic bonds. It is one of the most indispensable biological macromolecular substances in life's activities. In the past two decades, a large number of studies have found that non-starch natural polysaccharides isolated from various biological sources, such as animals, plants, microorganisms and algae have rich biological activities, such as immune regulation, anti-tumor, anti-oxidation, anti-radiation, anti-virus, hypolipidemic, hypoglycemic and antibacterial activities [9]. The molecular structure and spatial conformation of polysaccharides usually carry a lot of biological information and play a vital role in the life activities of organisms [10]. Among them, the triple helix polysaccharide is particularly noticeable. It was reported that polysaccharides, with triple-helical conformation, usually have good biological activity, such as lentinan [11], kelp polysaccharide [12], Schizophyllum polysaccharide [13], and Dianthus longifolia polysaccharide [14], etc. With the improvement in polysaccharide separation, purification and structural analysis technology, studies focuses on the structure and function of natural active polysaccharides have been continuously deepened, and polysaccharides have been found to have great research and utilization value in clinical medicine and health care product development. That is why polysaccharides become hot topics in the fields of natural medicine development and health food development.

Current reports on quinoa mainly focus on the study of protein, saponins and phenolic acids. However, there are few reports on the physicochemical and biological activity of quinoa polysaccharides. Therefore, the aim of this work was to evaluate the relationship between structural characteristics and biological activities of quinoa polysaccharide, which might provide useful guidance for exploiting quinoa polysaccharide for utilization in processed foods.

\section{Results and Discussion}

\subsection{Chemical Compositions of $Q P S$}

The yield and chemical component of QPs prepared by ethanol fractional precipitation are shown in Table 1. The yield of QPs was in the following order from low to high: QPE90 < QPE50 < QPE80 < QPE60 $<$ QPE70. Using glucose as the standard, the total sugar content of QPE70 was estimated to be 67.15\%, which was higher than that of QPE90 (41.01\%), QPE80 (44.56\%), QPE50 (52.82\%) and QPE60 (63.69\%).

The content of uronic acid in polysaccharide could enable polysaccharide to be negatively charged, which had an important effect on the biological activity of polysaccharide [15]. From the above result, QPE70 had the highest uronic acid content compared with other QPs sample.

Molecular weight is an important feature of polysaccharides, which is closely related to the structure and biological activity of polysaccharide. The average molecular weight of QPs obtained by gradient ethanol precipitation gradually decreased as the ethanol concentration increased (Table 1). In addition, the polydispersity index $(\mathrm{Mw} / \mathrm{Mn})$ of five polysaccharides were less than 2, which means that molecules were less dispersed in the aqueous solution [16]. Furthermore, the polysaccharide molecules start to dehydrate when ethanol was added to a solution containing polysaccharide, and then polysaccharide conformation was transformed and assembled, due to the enhancement 
of intramolecular hydrogen bonding [17]. As reported in the literature, different average molecular weights of polysaccharide fractions could be precipitated by gradient ethanol [18].

Table 1. Yield, chemical composition and molecular weight of QPs precipitated by gradient ethanol.

\begin{tabular}{cccccc}
\hline \multirow{2}{*}{ Index } & \multicolumn{5}{c}{ Samples } \\
\cline { 2 - 6 } & QPE50 & QPE60 & QPE70 & QPE80 & QPE90 \\
\hline Yield (w \%) & $0.84 \pm 0.03$ & $1.95 \pm 0.02$ & $2.26 \pm 0.31$ & $1.45 \pm 0.26$ & $0.74 \pm 0.02$ \\
Total sugar (w \%) & $52.82 \pm 0.02$ & $63.69 \pm 0.07$ & $67.15 \pm 1.32$ & $44.56 \pm 1.32$ & $41.01 \pm 2.58$ \\
Uronic acid (w \%) & $20.84 \pm 1.23$ & $21.51 \pm 1.21$ & $31.30 \pm 1.62$ & $19.61 \pm 1.22$ & $25.88 \pm 1.16$ \\
Protein (w \%) & $11.13 \pm 0.69$ & $8.54 \pm 1.06$ & $9.50 \pm 0.75$ & $7.01 \pm 0.74$ & $3.32 \pm 0.08$ \\
\cline { 2 - 6 } Average Molecular Weights (Da) & & & & \\
Mw & 13,785 & 6489 & 4732 & 3318 & 1960 \\
Mn & 8265 & 5206 & 4082 & 2943 & 1689 \\
Mw/Mn & 1.67 & 1.25 & 1.16 & 1.13 & 1.16 \\
\hline
\end{tabular}

\subsection{Monosaccharide Composition of $Q P S$}

The biological activity of polysaccharide is usually affected by their monosaccharide compositions. The monosaccharide compositions of different QPs were analyzed by HPLC (Table 2 and Figure 1 ). According to the monosaccharide standards, QPE50 was composed of glucose and arabinose with the molar ratio of 94.37:5.63, QPE60 was composed of rhamnose, glucose, galactose and arabinose with the molar ratio of 0.73:87.92:4.67:6.68, QPE70 was composed of glucose, galactose and arabinose with the molar ratio of 92.21:2.98:4.81, while QPE80 and QPE90 were all composed of glucose. Glucose was a predominantly monosaccharide in these QPs, which was consistent with the results from previous report [19].

Table 2. Monosaccharide composition of different QPs components.

\begin{tabular}{cccccc}
\hline \multirow{2}{*}{$\begin{array}{c}\text { Monosaccharide } \\
\text { Composition }\end{array}$} & QPE50 & QPE60 & QPE70 & QPE80 & QPE90 \\
\cline { 2 - 5 } & - & $0.73 \pm 0.04$ & - & - & - \\
\hline L-Rhamnose & $94.37 \pm 1.25$ & $87.92 \pm 2.56$ & $92.21 \pm 2.57$ & $100 \pm 1.27$ & $100 \pm 1.79$ \\
D-Glucose & - & $4.67 \pm 0.39$ & $2.98 \pm 0.03$ & - & - \\
D-Galactose & $5.63 \pm 0.06$ & $6.68 \pm 0.05$ & $4.81 \pm 0.04$ & - & - \\
D-Arabinose & & & &
\end{tabular}

\subsection{Congo Red Test}

The polysaccharide sample with a triple-helix structure, can form a complex with Congo red under weak alkaline conditions, and its UV absorption will be red-shifted compared to Congo red. With the $\mathrm{NaOH}$ concentration gradient increased in the reaction system, the hydrogen bond between polysaccharide molecules broken, and the triple-helix structure decomposed into a single strand, which could not form a complex with Congo red and became a random coil, and $\lambda$ max decreased sharply. It was reported that polysaccharide with triple helixes have high biological activity [20].

The results of the Congo red assay for each sample of QPs are shown in Figure 2. It can be seen from the figure that under weak alkaline conditions $(\mathrm{NaOH}$ concentration less than $0.1 \mathrm{~mol} / \mathrm{L}$ ), the $\lambda$ max of QPs mixed with Congo red showed a significant redshift. However, the $\lambda$ max decreased sharply as the continuously increase of $\mathrm{NaOH}$ concentration. For the blank control group without polysaccharide, $\lambda$ max also decreased as the continuously increase of $\mathrm{NaOH}$ concentration. These results suggested that there was a triple-helix structure in all QPs samples. 

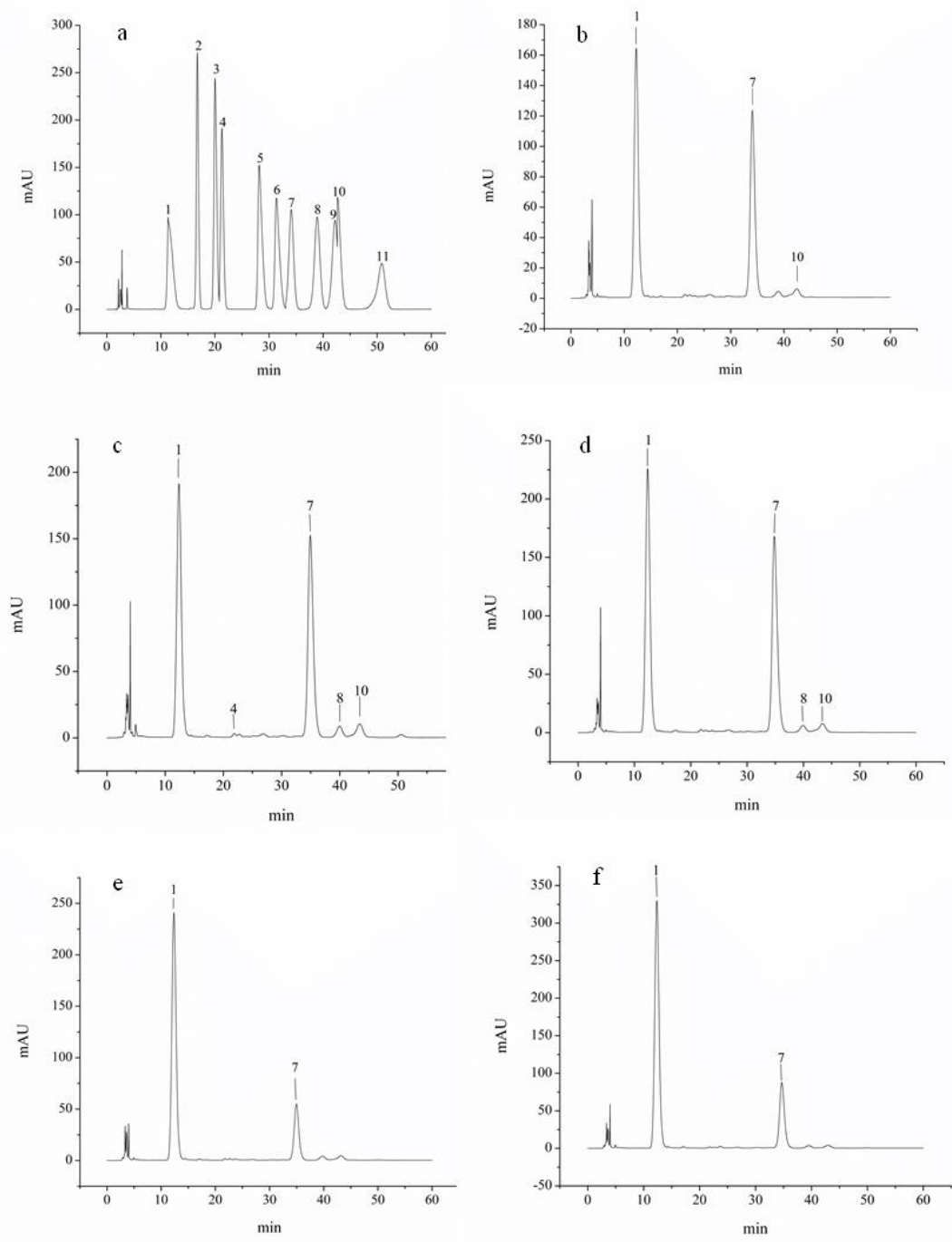

Figure 1. HPLC chromatogram of standard monosaccharide and QPs (a) standard monosaccharide, (b) QPE50, (c) QPE60, (d) QPE70, (e) QPE80, (f) QPE90 (1. PMP, 2. Mannose, 3. Ribose, 4. Rhamnose, 5. Glucuronic acid, 6. Galacturonic acid, 7. Glucose, 8. Galactose, 9. Xylose, 10. Arabinose, 11. Fucose).

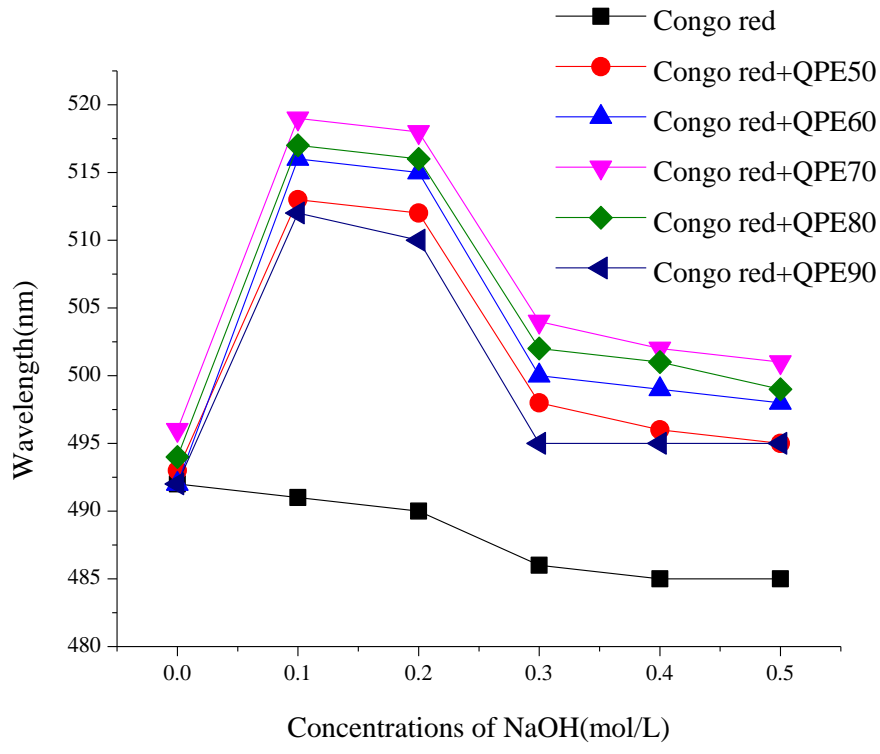

Figure 2. Congo red test results of QPs. 


\subsection{UV and FT-IR Spectroscopy of QPS}

The ultraviolet spectrum of QPs obtained by gradient ethanol precipitation is shown in Figure 3A. It could be observed that there was an obvious absorption peak around $280 \mathrm{~nm}$ in all QPs samples, indicating that protein was the component, which was consistent with the polysaccharide component analysis.

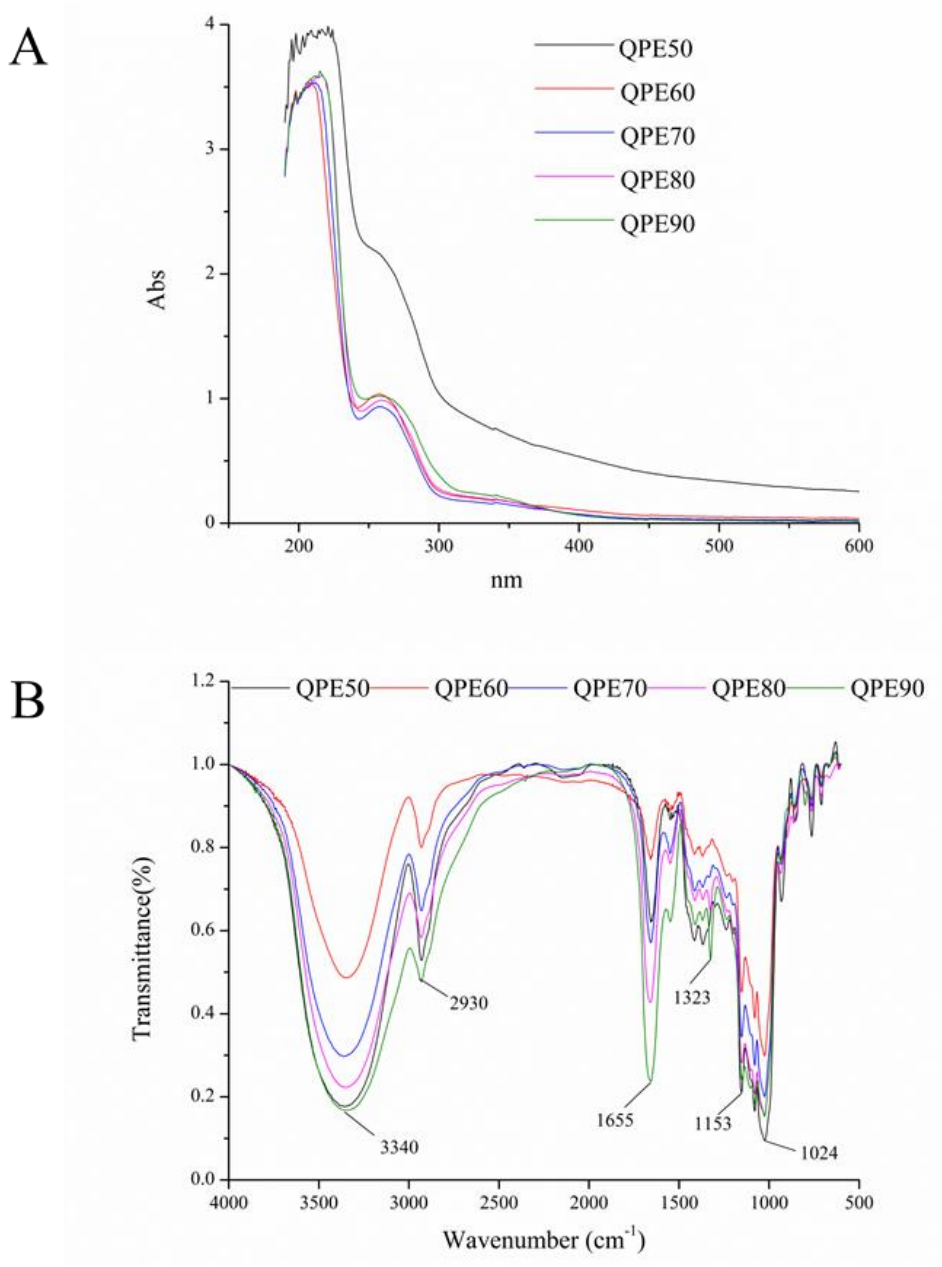

Figure 3. Ultraviolet spectrum (A) and FT-IR spectrum (B) of QPs.

The FT-IR spectrum of QPs is shown in Figure 3B, in which the typical absorption of polysaccharide could be observed. It could be found that QPE50, QPE60, QPE70, QPE80, QPE90 had similar absorption band from $4000 \mathrm{~cm}^{-1}$ to $400 \mathrm{~cm}^{-1}$. The absorption peak around $3340 \mathrm{~cm}^{-1}$ was contributed by $-\mathrm{OH}$ stretching vibration, demonstrating the existing of $-\mathrm{OH}$. The weak absorption around $2930 \mathrm{~cm}^{-1}$ was $\mathrm{C}-\mathrm{H}$ stretching vibration, including $-\mathrm{CH}_{2},-\mathrm{CH}_{3}$. The strong peak at approximately $1653 \mathrm{~cm}^{-1}$ belonged to the $-\mathrm{C}=\mathrm{O}$ stretching vibration, while the peak at around $1153 \mathrm{~cm}^{-1}$ indicated the existence of pyranose, which was matched the result of monosaccharide composition analysis. Furthermore, the peak around $920 \mathrm{~cm}^{-1}$ was the representative absorption of $\beta$ configuration [21]. The FT-IR spectra of QPs were characteristic absorption peaks of polysaccharides, which may be consistent with $\beta$-glucans.

\subsection{SEM Analysis}

The SEM images of QPs are shown in Figure 4, which showed the samples morphology. From the above molecular weight analysis, it could be found that the molecular weight of QPE-50, QPE-60, QPE-70, QPE-80, QPE-90 was gradually decreasing. We can see that QPs particles shrink with the reduction of molecular weight. The particles were separated from each other. This phenomenon could be explained by hydrogen bonds exist in polysaccharide. Polysaccharide with higher molecule weight 
are more likely to form hydrogen bonds between polysaccharides, while polysaccharides with low molecule weight tend to form hydrogen bonds with water. Polysaccharides are dissolved in water through the formation of hydrogen bonds between polysaccharide and water. When ethanol was added to a solution containing polysaccharide, polysaccharide with high molecule weight were rapidly precipitated, due to the formation of a large number of intermolecular hydrogen bonds. Therefore, they exhibit a relatively aggregated state, while polysaccharide with low molecule weight are more likely to form hydrogen bonds, with water and difficult to aggregate with each other, so as to show a relatively dispersed state.
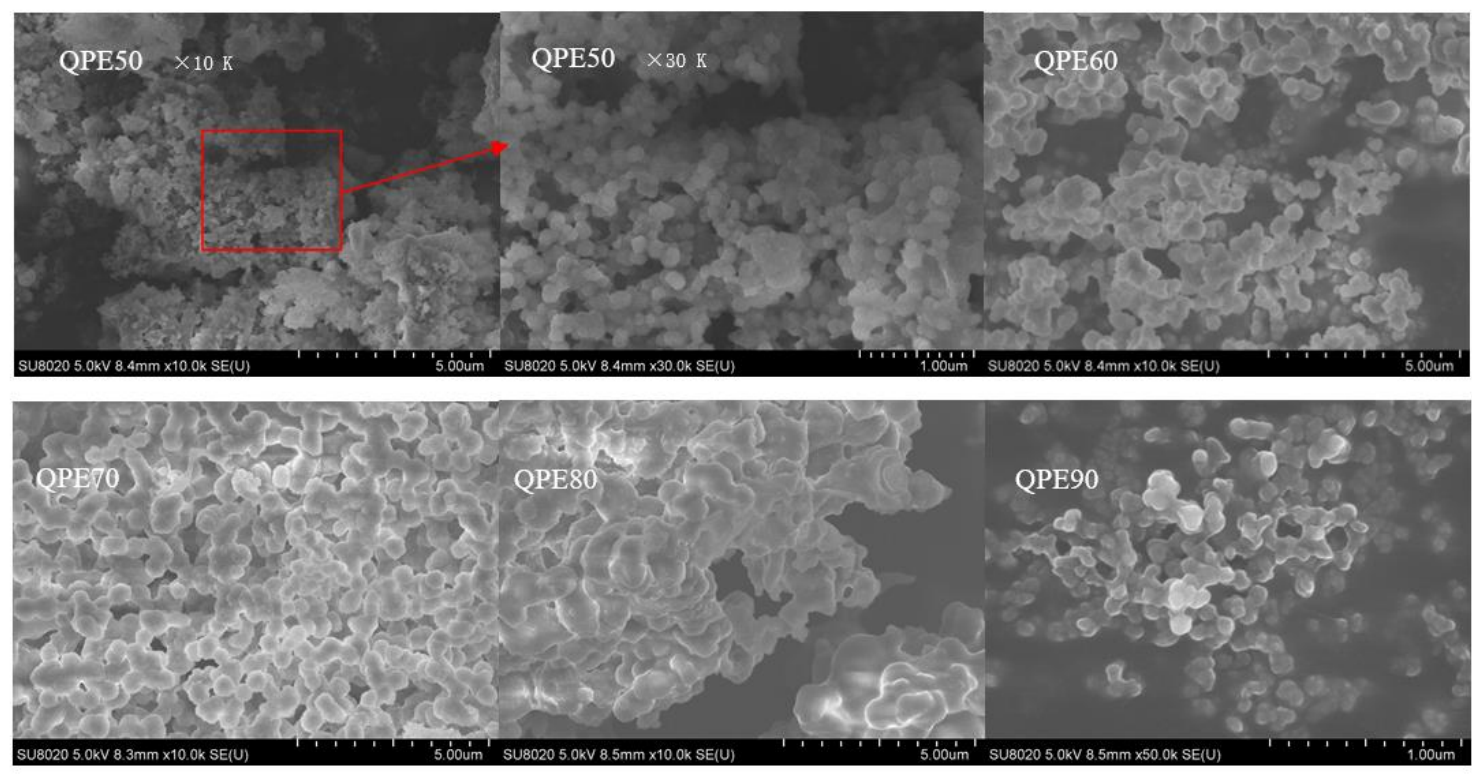

Figure 4. SEM images of QPs.

\subsection{AFM Analysis}

The AFM is a powerful technology to observe the molecular morphology of polysaccharides [22-24]. AFM images of QPs are shown in Figure 5. As can be seen from the images that apart from QPE80, all other QPs samples showed granular or spherical particles with irregular shape and size. The width of four polysaccharide chains were in the range of $0.146-0.166 \mu \mathrm{m}, 0.101-0.123 \mu \mathrm{m}, 0.072-0.096 \mu \mathrm{m}$ and $0.052-0.079 \mu \mathrm{m}$, respectively. QPE80 appeared linear in structure and branched or coiled in water solution, the width of the polysaccharide chain was range from 0.022 to $0.046 \mu \mathrm{m}$, and the length was in the range of $0.737-1.728 \mu \mathrm{m}$. A helical conformation could be seen in the AFM image of QPE80.

Generally, the width of a single polysaccharide chain is between 0.1 and $1 \mathrm{~nm}$ [25]. From our results, the width of the QPs chain was more than $20 \mathrm{~nm}$, which was much larger than a single polysaccharide chain, indicating that the polysaccharide unit could be branched and tangled with each other. As observed in the morphology of polysaccharide chains, QPs with higher Mw values had a wider polysaccharide chain, which was also due to their aggregation. 

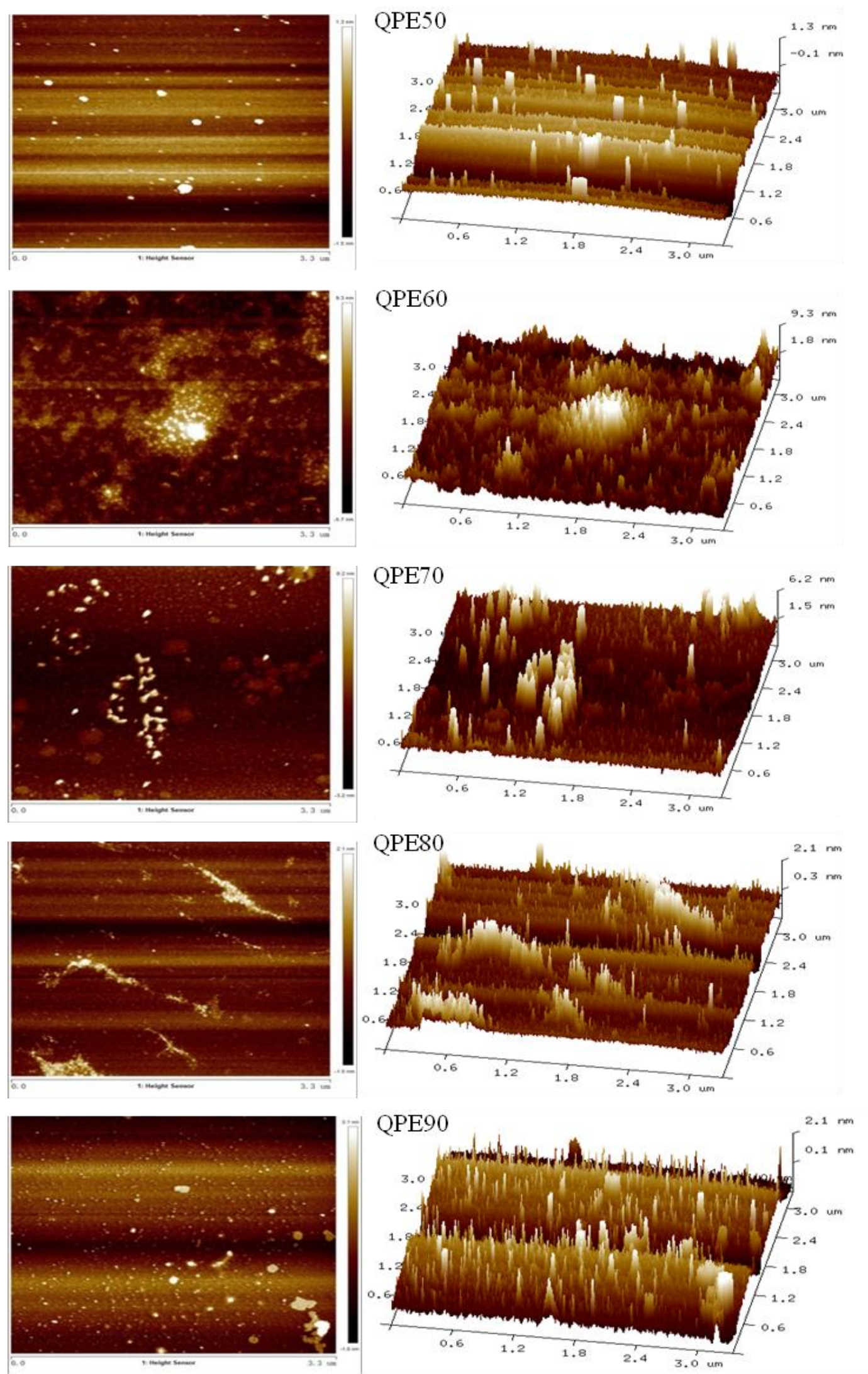

Figure 5. Atomic force microscope images (2D/3D) of QPs. 


\subsection{XRD Analysis}

XRD technology is an important analytical tool to investigate the crystal structure of high molecular polymers. Generally, polysaccharides are relatively difficult to crystallize, and single crystal morphology is difficult to obtain using XRD analysis. According to reports in the literature, only some polysaccharides with rigid helix chains exist in crystalline form, due to their ordered structure [26].

The XRD patterns recorded for QPs were between $5^{\circ}$ and $90^{\circ}$ (Figure 6). As can be seen from the figure, all five QPs showed low overall crystallinity and had a clear diffraction peak when $2 \theta$ was about $20.2^{\circ}$. This result revealed that the QPs were semi-crystalline polymers and possessed an ordered helical structure that could be related to their biological activity. According to the literature reported before $[27,28]$, diffraction peaks were also observed in other polysaccharides when $2 \theta$ was about $20^{\circ}$. The crystal structure characteristics of polysaccharide directly determine its physical properties such as solubility, tensile strength, swelling, flexibility, or opaqueness [29]. In fact, the biological activity of polysaccharide is also affected by its crystal structure characteristics [30].

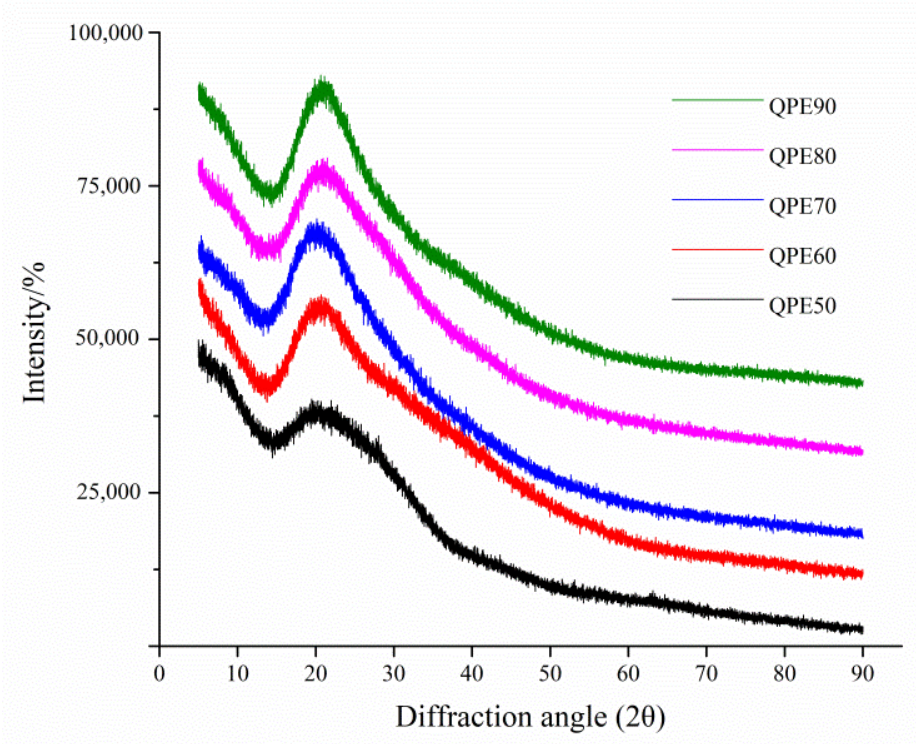

Figure 6. XRD patterns of QPs.

\subsection{TG-DTA-DTG Analysis}

Thermogravimetric analysis uses temperature as the abscissa and the weight loss rate of the sample as the ordinate, and records the weight change of the sample during the heating process to obtain the thermogravimetric curve, also known as the TG curve. Information, such as the thermal stability, thermal decomposition temperature, thermally stable temperature range, and composition of the substance can be obtained from the thermogravimetric curve. The DTG curve is obtained by taking the first derivative of the thermogravimetric curve against the temperature, and reflects the relationship between the rate of change of the sample mass and the temperature. The DTA method is a thermal analysis method to measure the temperature difference between sample and reference substance under the temperature condition of the program control.

The TG-DTA-DTG results of QPs are shown in Figure 7. For QPE50, from the TG curve, there is a $7.41 \%$ weight loss in the range of $50-150{ }^{\circ} \mathrm{C}, 54.73 \%$ weight loss in the range of $150-500{ }^{\circ} \mathrm{C}$, and $6.09 \%$ weight loss in the range of $500-800^{\circ} \mathrm{C}$. DTG curve shows that there are two major weight loss stages, $150-250{ }^{\circ} \mathrm{C}$ and $250-400{ }^{\circ} \mathrm{C}$. The maximum weight loss rate are at $200.98^{\circ} \mathrm{C}$ and $325.11^{\circ} \mathrm{C}$, respectively. For QPE60, from the TG curve, there is a $8.7 \%$ weight loss in the range of $50-150{ }^{\circ} \mathrm{C}, 53.52 \%$ weight loss in the range of $150-500{ }^{\circ} \mathrm{C}$, and $3.85 \%$ weight loss in the range of $500-800{ }^{\circ} \mathrm{C}$. DTG curve shows that the maximum weight loss rate are at $200.28^{\circ} \mathrm{C}$ and $337.41^{\circ} \mathrm{C}$ in the two major weight loss stages. For QPE70, from the TG curve, there is a $6.98 \%$ weight loss in the range of $50-150{ }^{\circ} \mathrm{C}, 44.65 \%$ weight 
loss in the range of $150-500{ }^{\circ} \mathrm{C}$, and $2.81 \%$ weight loss in the range of $500-800{ }^{\circ} \mathrm{C}$. DTG curve shows that the maximum weight loss rate are at $195.98^{\circ} \mathrm{C}$ and $318.18{ }^{\circ} \mathrm{C}$ in the two major weight loss stages. For QPE80, from the TG curve, there is a $9.4 \%$ weight loss in the range of $50-150{ }^{\circ} \mathrm{C}, 48.59 \%$ weight loss in the range of $150-500{ }^{\circ} \mathrm{C}$, and $3.32 \%$ weight loss in the range of $500-800{ }^{\circ} \mathrm{C}$. DTG curve shows that the maximum weight loss rate are at $188.86{ }^{\circ} \mathrm{C}$ and $324.16^{\circ} \mathrm{C}$ in the two major weight loss stages. For QPE90, from the TG curve, there is a $7.6 \%$ weight loss in the range of $50-150{ }^{\circ} \mathrm{C}, 45.69 \%$ weight loss in the range of $150-500{ }^{\circ} \mathrm{C}$, and $6.98 \%$ weight loss in the range of $500-800{ }^{\circ} \mathrm{C}$. DTG curve shows that the maximum weight loss rate are at $149.37^{\circ} \mathrm{C}$ and $313.27^{\circ} \mathrm{C}$ in the two major weight loss stages. The DTA curve of all five QPs samples indicated that the decomposition of graded alcohol-precipitated QPs was an exothermic reaction.
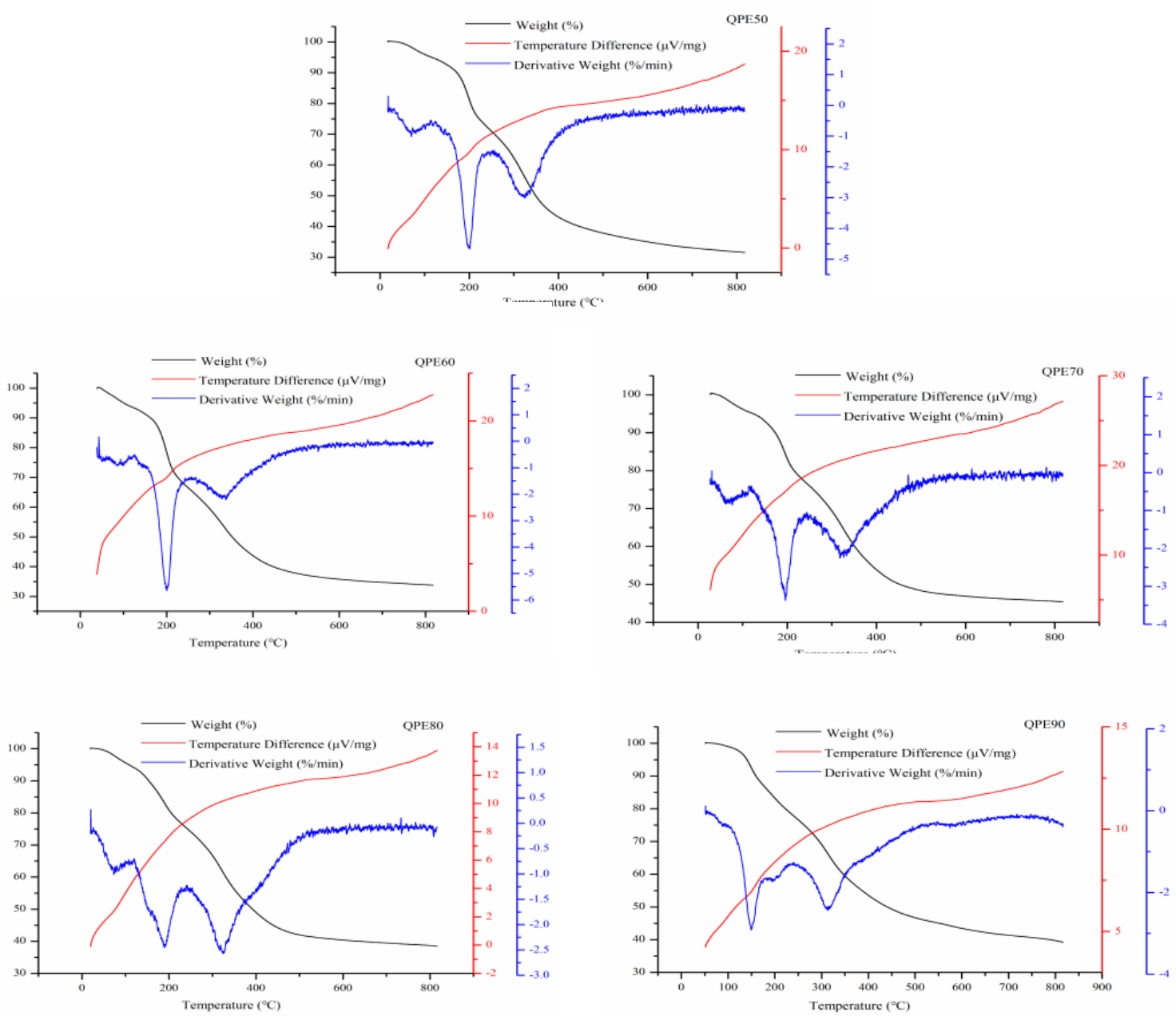

Figure 7. TG-DTA-DTG curves of QPs.

\subsection{Biological Activity of QPS}

\subsubsection{Antioxidant Activities of QPs}

The DPPH and ABTS radical scavenging capability have been widely used to investigate the total antioxidant activity of polysaccharides [31]. The scavenging activity of QPs on DPPH and ABTS radicals was presented in Table 3. As shown in Table 3, different components of quinoa polysaccharide all exhibited scavenging effects on ABTS and DPPH. QPE90 has the strongest ability to scavenge DPPH and ABTS radicals. The $\mathrm{EC}_{50}$ values were determined as $5.22 \mathrm{mg} / \mathrm{mL}$, and $1.83 \mathrm{mg} / \mathrm{mL}$, respectively. QPE50 has the weakest scavenging ability. The order of scavenging DPPH ability was QPE90 > QPE80 > QPE70 > QPE50 > QPE60. The order of scavenging ABTS ability was QPE90 > QPE70 > 
QPE80 > QPE60 > QPE50. From the above results, we could see that QPE90 showed the strongest antioxidant activity.

Table 3. Antioxidant, antidiabetic activities and glycemic index of QPs.

\begin{tabular}{|c|c|c|c|c|c|}
\hline \multirow{2}{*}{$\begin{array}{c}\text { Quinoa } \\
\text { Polyssacharides }\end{array}$} & \multicolumn{2}{|c|}{ Antioxidant activity } & \multicolumn{2}{|c|}{ Antidiabetic Activity } & \multirow{2}{*}{$\begin{array}{c}\text { Glycemic } \\
\text { Index (GI) }\end{array}$} \\
\hline & $\begin{array}{c}\text { DPPH } \\
\mathrm{EC}_{50}(\mathrm{mg} / \mathrm{mL})\end{array}$ & $\begin{array}{c}\text { ABTS } \\
\mathrm{EC}_{50}(\mathrm{mg} / \mathrm{mL})\end{array}$ & $\begin{array}{c}\alpha \text {-Amylase } \\
\mathrm{IC}_{50}(\mathrm{mg} / \mathrm{mL})\end{array}$ & $\begin{array}{l}\alpha \text {-Glucosidase } \\
\mathrm{IC}_{50}(\mathrm{mg} / \mathrm{mL})\end{array}$ & \\
\hline QPE50 & $13.67 \pm 0.59 b$ & $5.21 \pm 0.27 a$ & $102.66 \pm 0.98 b$ & $92.38 \pm 0.66 a$ & $72.19 \pm 0.51 a$ \\
\hline QPE60 & $15.22 \pm 0.50 \mathrm{a}$ & $2.39 \pm 0.05 b$ & $105.73 \pm 1.60 \mathrm{a}$ & $81.79 \pm 0.77 b$ & $68.37 \pm 0.39 b$ \\
\hline QPE70 & $8.19 \pm 0.57 c$ & $2.13 \pm 0.06 b$ & $82.17 \pm 0.95 c$ & $53.26 \pm 1.02 d$ & $65.40 \pm 0.35 c$ \\
\hline QPE80 & $8.06 \pm 0.53 c$ & $2.22 \pm 0.12 b$ & $72.99 \pm 0.90 \mathrm{~d}$ & $57.28 \pm 0.59 c$ & $65.92 \pm 0.37 c$ \\
\hline QPE90 & $5.22 \pm 0.47 d$ & $1.83 \pm 0.03 b$ & $61.36 \pm 0.58 \mathrm{e}$ & $48.67 \pm 0.65 \mathrm{e}$ & $61.68 \pm 0.22 d$ \\
\hline Vc & $0.01 \pm 0.00 \mathrm{e}$ & $0.01 \pm 0.00 c$ & - & - & - \\
\hline Acarbose & - & - & $2.65 \pm 0.32 f$ & $0.23 \pm 0.01 \mathrm{f}$ & - \\
\hline
\end{tabular}

\subsubsection{Alpha-Amylase and Alpha-Glucosidase Inhibitory Activities of QPs}

Alpha-amylase and alpha-glucosidase inhibitors could delay the release of glucose or fructose in the small intestine, and subsequently reduce postprandial hyperglycaemia [32]. Therefore, these inhibitors may be promising oral hypoglycemic agents for preventing type 2 diabetes. As shown in Table 3 , different components of QPs all exhibited antidiabetic activity. QPE90 has the best inhibitory effects on $\alpha$-amylase and $\alpha$-glucosidase. The $\mathrm{IC}_{50}$ values were determined as $48.67 \mathrm{mg} / \mathrm{mL}$ and $61.36 \mathrm{mg} / \mathrm{mL}$. QPE50 has the lowest inhibitory effects. The order of $\alpha$-amylase inhibitory activity was QPE90 $>$ QPE80 $>$ QPE70 $>$ QPE50 > QPE60, and the order of $\alpha$-glucosidase inhibitory activity was QPE90 > QPE70 > QPE80 > QPE60 > QPE50. From the above results, we could see that QPE90 showed the best antidiabetic activity.

\subsubsection{Glycemic Index of QPs}

GI is an indicator to measure the effect of carbohydrates on blood glucose levels, and is also a tool for type II diabetes diet management $[33,34]$. When GI is equal to, or higher than, 70 at the glucose level, carbohydrate foods are regarded as high GI foods that can be quickly digested and absorbed. While, when GI is equal to, or lower than, 55 at the glucose level, carbohydrate foods are considered low GI foods that digested and absorbed slowly. Low GI foods could reduce postprandial blood glucose levels, and this knowledge can be used to recommend and plan diets for people with diabetes [35].

As can be seen from Table 3, except for QPE50, all other QPs have a GI lower than 70. The GI value order of QPs was QPE50 > QPE60 > QPE80 > QPE70 > QPE90, which was significantly negatively correlated with the $\alpha$-glucosidase inhibitory activity. $\alpha$-glucosidase and $\alpha$-amylase are key enzymes for carbohydrate digestion in the diet, and inhibitors of these enzymes may effectively delay the absorption of glucose [36]. Inhibition of $\alpha$-glucosidase could slow down the decomposition of disaccharides into simple glucose, thereby reducing the amount of glucose absorbed in the blood, which affects the GI. This laid the foundation for the hypothesized mechanism of $\alpha$-amylase and $\alpha$-glucosidase inhibitors to reduce the GI. Therefore, we can conclude that the hypoglycemic potential of QPs is associated with their GI value and inhibition of $\alpha$-amylase and $\alpha$-glucosidase.

\section{Materials and Methods}

\subsection{Materials}

Quinoa seeds were purchased from Dulan, Qinghai province (China). Phenol, sulfuric acid, carbazole, bovine serum albumin, coomassie blue G-250, phosphoric acid, ethanol (China national pharmaceutical group, Beijing, China), chloroform, monosaccharide control (glucose, galactose, arabinose, xylose, mannose, rhamnose, ribose and fucose were purchased from Sino Pharm Chemical Reagent Co., Ltd. (Beijing, China), 
glucuronic acid and galacturonic acid were purchased from Sigma Co., Ltd., St. Louis, MO, USA). All other reagents were analytically pure.

\subsection{Extraction and Isolation of Quinoa Polysaccharide (QPs)}

One hundred gram quinoa seeds powder and $1000 \mathrm{~mL}$ distilled water were added in a container, the extraction was performed at $60{ }^{\circ} \mathrm{C}$ for $2 \mathrm{~h}$, and repeated twice. The filtrates were combined, concentrated by a vacuum rotary evaporator, and precipitated with 3 vol of $95 \%$ ethanol at $4{ }^{\circ} \mathrm{C}$ for $12 \mathrm{~h}$, followed by centrifugation at $4000 \mathrm{rpm}$ for $10 \mathrm{~min}$. The precipitate was washed by ethanol, acetone and ether, and then dissolved in hot water. Quinoa polysaccharides (QPs) were fractionated by using the gradient ethanol precipitation method. The scheme is illustrated in Figure 8. Briefly, ethanol was added into the solution to make an ethanol concentration of $50 \%$, and followed by a refrigeration at $4{ }^{\circ} \mathrm{C}$ for $12 \mathrm{~h}$, centrifugation and freeze-dry to obtain Quinoa polysaccharide (QPE50). For the supernatant of QPE50, ethanol was added into the solution to make an ethanol concentration of $60 \%$, then refrigeration, centrifugation and freeze-dry to obtain QPE60. QPE70, QPE80, and QPE90 were prepared by gradient ethanol in sequence.

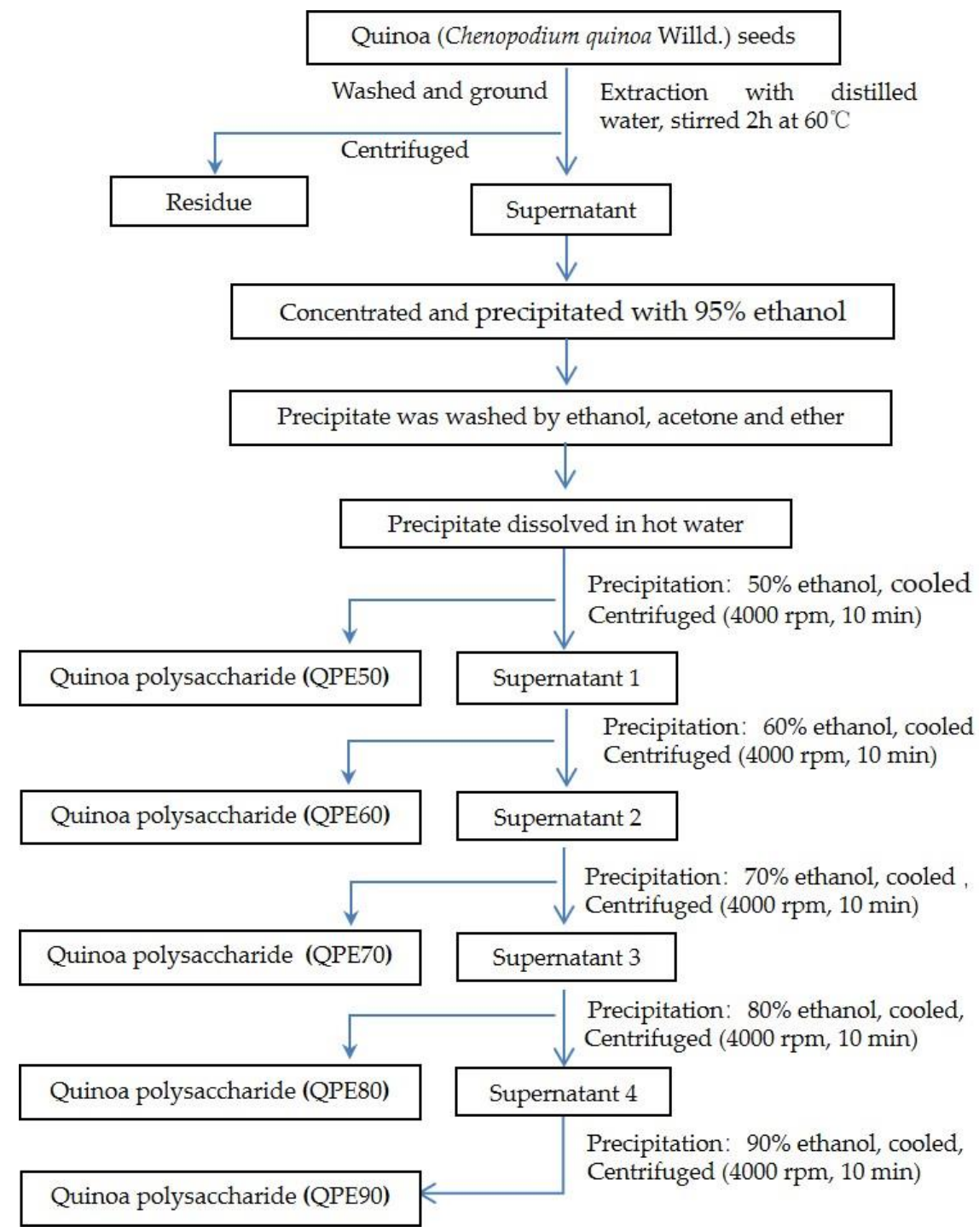

Figure 8. Flow chart of extraction and isolation of polysaccharides from quinoa. 


\subsection{Structure and Physicochemical Properties of QPS}

3.3.1. Determination of Polysaccharide Yield, Chemical Composition and Average Molecular Weight of QPs

The content of total sugar in QPs was determined by the phenol-sulfuric acid method using glucose as the standard [37]. The protein content was determined by photometric assay according to the Bradford method using bovine serum albumin (BSA) as the standard [38]. The uronic acid content was determined by a carbazole-sulfuric acid method using galacturonic acid as the standard [39].

Polysaccharide yield is calculated by the following formula,

$$
\omega_{1}(\%)=100 \times \mathrm{m}_{1} / \mathrm{m}_{2}
$$

where $\omega_{1}(\%)$ is the polysaccharide yield, $\mathrm{m}_{1}(\mathrm{mg})$ is the weight of QPs, and $\mathrm{m}_{2}(\mathrm{mg})$ is the weight of quinoa seed used for extraction.

The high performance gel permeation chromatography (HPGPC-RID, Agilent1260, Santa Clara, CA, USA) equipped with a TSKgel G4000 pwXL column $(7.8 \mathrm{~mm} \times 300 \mathrm{~mm}, 8 \mu \mathrm{m})$ was used to measure the molecular weight of QPs according to the method described by Zhu et al. (2019) [40]. The detector temperature was $35^{\circ} \mathrm{C}$, the mobile phase was deionized water, and the flow rate was $0.8 \mathrm{~mL} \cdot \mathrm{min}^{-1}$. Dextran standards with different molecular weights (T-10, T-25, T-40, T-70, T-500, and T-2000) were used to establish the standard curve for calibration.

\subsubsection{Monosaccharide Composition Analysis}

The assay for monosaccharide composition was carried out according to the method of Dai with some modifications [41]. The polysaccharide sample $(10 \mathrm{mg})$ was placed in a hydrolysis tube and hydrolyzed with $1.0 \mathrm{~mL}$ of $2.0 \mathrm{M}$ trifluoroacetic acid (TFA) at $120^{\circ} \mathrm{C}$ for $2 \mathrm{~h}$, and then dried under nitrogen. Afterwards, $1 \mathrm{~mL}$ of $0.5 \mathrm{M}$ 1-phenyl-3-methyl-5-pyrazolone (PMP) methanol solution and $0.5 \mathrm{~mL}$ of $0.3 \mathrm{M} \mathrm{NaOH}$ solution were added to the hydrolysate to be derived in a $70{ }^{\circ} \mathrm{C}$ water bath for $2 \mathrm{~h}$. After cooling to room temperature, $0.5 \mathrm{~mL}$ of $0.3 \mathrm{M} \mathrm{HCl}$ solution was added, then $0.5 \mathrm{~mL}$ of chloroform was added for extraction, shaken thoroughly, and then allowed to stand for $20 \mathrm{~min}$. The lower layer was discarded, and the upper layer was extracted twice with chloroform to obtain derivative products.

The derivative products were analyzed by HPLC (Agilent 1260 HPLC, Santa Clara, CA, USA) with a diode array detector and a $\mathrm{C}_{18}$ column $(4.6 \mathrm{~mm} \times 250 \mathrm{~mm}$ i.d., $5 \mu \mathrm{m}$, Waters). The eluted mobile phase was $0.1 \mathrm{M} \mathrm{KH}_{2} \mathrm{PO}_{4}$ solution $(\mathrm{pH}=6.8$, solvent $\mathrm{A}$ ) and acetonitrile (solvent $\mathrm{B}$ ), and used at $82 \%$ $\mathrm{A}$ and $18 \% \mathrm{~B}$. The flow rate was $1.0 \mathrm{~mL} / \mathrm{min}$, the column temperature was $25^{\circ} \mathrm{C}$, and the detection wavelength was at $245 \mathrm{~nm}$. Monosaccharides glucose, galactose, xylose, mannose, ribose, rhamnose, glucuronic acid, galacturonic acid, arabinose and fucose were used as references.

\subsubsection{Congo Red Test}

The Congo red test of QPs was analyzed by spectrophotometry method [42]. The sample solution $(0.5 \mathrm{mg} / \mathrm{mL})$ was mixed with $2 \mathrm{~mL}, 50 \mu \mathrm{M}$ Congo red and $1 \mathrm{M} \mathrm{NaOH}$ to achieve a final $\mathrm{NaOH}$ concentration of $0-0.50 \mathrm{M}$. At the same time, a mixed solution without polysaccharide was prepared as the control. The UV-vis absorption spectrum was measured in the range of 200 to $700 \mathrm{~nm}$ after equilibration at room temperature for $10 \mathrm{~min}$.

\subsubsection{UV-VIS Spectroscopy and Fourier Transform Infrared Spectroscopy (FT-IR)}

Each QPs sample was prepared with a mass concentration of about $2 \mathrm{mg} \cdot \mathrm{mL}^{-1}$, and the spectroscopic analysis was performed at 200-600 $\mathrm{nm}$ by a UV-VIS spectrophotometer (Unico, Shanghai, China).

FT-IR spectra of QPs was analysed. All samples within KBr pellet were determined using FT-IR (TENSER 27, Bruker, Karlsruhe, Germany) with a spectral range of 4000 to $400 \mathrm{~cm}^{-1}$. 


\subsubsection{Scanning Electron Microscopy}

The surface microstructure of QPs was observed by a scanning electron microscopy (JSM-6700F, JEOL, Tokyo, Japan). The specimens were fixed on a metal stub with silver conductive tape, and were sputtered with gold using a sputter coater.

\subsubsection{Atomic Force Microscope (AFM) Observation}

The purified QPs were dissolved in distilled water to a solution concentration of $10 \mu \mathrm{g} / \mathrm{mL} .10 \mu \mathrm{L}$ of the sample solution was dropped on the surface of cleaved mica $(\varphi 1 \mathrm{~cm})$, and dried at $25^{\circ} \mathrm{C}$. Atomic force microscope (AFM, Bruker, Karlsruhe, Germany) was used for the determination of QPs morphology in the ambient condition under tapping mode [14].

\subsubsection{XRD Analysis}

The X-ray diffraction patterns of the QPs were measured by a Rigaku Smartlab X-ray diffractometer equipped with a $\mathrm{Cu}-\mathrm{K} \beta$ radiation source. The operating conditions of the diffractometer were: step size $0.01^{\circ}$, scan speed $15^{\circ} \mathrm{min}^{-1}$, tube pressure $40 \mathrm{kv}$, tube flow $200 \mathrm{~mA}$, angular range of 5-90 $(2 \theta)$.

\subsubsection{Thermal Analysis}

Thermogravimetric analyzer (TG-DTA 6300, Tokyo, Japan) was used to investigate the weight loss stages of QPs. In the TGA experiment, the sample powders are heated from 50 to $800{ }^{\circ} \mathrm{C}$ with a heating rate of $10^{\circ} \mathrm{C} / \mathrm{min}$ under the nitrogen atmosphere. The weight of the sample was less than $5 \mathrm{mg}$ to avoid the possible temperature gradient inside the sample and ensure the kinetic control of the process.

\subsection{Determination of Biological Activity}

\subsubsection{DPPH Radical Scavenging Activity}

The DPPH free radical scavenging activity of QPs was measured according to previous method [43] with some modifications. Three milliliter of freshly prepared DPPH ( $0.1 \mathrm{mM}$ in $50 \%$ ethanol) is added as a free radical source to $1 \mathrm{~mL}$ containing various concentrations $(0,0.25,0.5,0.75,1.0,2.0,5.0,10.0$ and $20.0 \mathrm{mg} / \mathrm{mL}$ ). The mixture was shaken rapidly for $5 \mathrm{~min}$ and incubated at $25^{\circ} \mathrm{C}$ for $25 \mathrm{~min}$. Vc was used as a positive control, and the absorbance was measured at $517 \mathrm{~nm}$. The capability to scavenge the DPPH radical was calculated, using the following equation,

$$
\text { DPPH scavenged }(\%)=\left(1-\frac{\mathrm{As}-\mathrm{Asb}}{\mathrm{Ac}-\mathrm{Acb}}\right) \times 100
$$

where Ac represents the absorption of the negative control (DPPH with solvent), Acb represents the absorption of the system background (50\% ethanol with solvent), As represents the absorption of the DPPH system with added sample, and Asb represents the absorption of the sample background (50\% ethanol with sample). From a plot of concentration against \% scavenging activity, a linear regression analysis was performed to determine the $\mathrm{EC}_{50}$ value of the sample.

\subsubsection{ABTS Radical Scavenging Activity}

The 2,2'-azino-bis(3-ethylbenzothiazoline-6-sulfonic acid) (ABTS) radical cation (ABTS ${ }^{+}$) scavenging activity of QPs was measured based on reported method [44]. Briefly, the ABTS solution $(7 \mathrm{mM})$ was mixed with potassium persulfate solution $(2.45 \mathrm{mM})$ in the dark for $12-16 \mathrm{~h}$. The prepared ABTS solution was diluted 40-50 times with phosphate buffer ( $\mathrm{pH} 7.4$ ), to make its absorbance of $0.70 \pm 0.02$ at $734 \mathrm{~nm}$. Then $0.4 \mathrm{~mL}$ of various concentrations $(0,0.25,0.5,0.75,1.0,2.0,5.0,10.0$ and $20.0 \mathrm{mg} / \mathrm{mL}$ ) of sample solution were added to $3 \mathrm{~mL}$ of $\mathrm{ABTS}^{+} \bullet$ solution. The solution was shaken rapidly until the absorbance became stable within $10 \mathrm{~min}$ at room temperature. The absorbance was 
measured at $734 \mathrm{~nm}$, and Vc was used as a positive control. The capability to scavenge the ABTS radical was calculated based on the following equation,

$$
\text { ABTS scavenged }(\%)=\left(1-\frac{A s-A s b}{A c-A c b}\right)=\times 100
$$

where Ac represents the absorption of the negative control (ABTS with solvent), Acb represents the absorption of the system background (phosphate buffer with solvent), As represents the absorption of the ABTS system with added sample, and Asb represents the absorption of the sample background (phosphate buffer with sample). The $\mathrm{EC}_{50}$ value of QPs samples was obtained from a linear regression analysis of concentration against $\%$ scavenging activity.

\subsubsection{Alpha-Amylase Inhibitory Activity}

The $\alpha$-amylase inhibitory activity of QPs was determined according to the reported method [45] with slight modifications. Briefly, $40 \mu \mathrm{L}$ of $0.2 \%$ (w/v) soluble starch, $20 \mu \mathrm{L}$ of QPs solution or $0.1 \mathrm{M}$ phosphate buffer (control) containing $6 \mathrm{mM} \mathrm{CaCl}_{2}$ (pH 6.9) and $20 \mu \mathrm{L}$ of $\alpha$-amylase dissolved in the above buffer were mixed in a 96-well plate to start the enzyme reaction. The reaction was stopped by adding $80 \mu \mathrm{L}$ of $0.4 \mathrm{M} \mathrm{HCl}$ after incubating at $37^{\circ} \mathrm{C}$ for $10 \mathrm{~min}$. The absorbance was read at $580 \mathrm{~nm}$ after $100 \mu \mathrm{L}$ of $5 \mathrm{mM} \mathrm{I}_{2}$ in $50 \mathrm{mM} \mathrm{KI}$ was added. Acarbose was used as positive control. The inhibitory activity of $\alpha$-amylase was calculated as follows,

$$
\text { inhibition }(\%)=\left(1-\frac{A_{4}-A_{3}}{A_{2}-A_{1}}\right)=\times 100
$$

where $A_{1}$ and $A_{2}$ were the absorbance of mixture containing starch and $\alpha$-amylase or starch only. $\mathrm{A}_{3}$ and $\mathrm{A}_{4}$ were the absorbance of mixture containing starch and QPs with or without $\alpha$-amylase. Inhibitory activity was expressed as $\mathrm{IC}_{50}$ value.

\subsubsection{Alpha-Glucosidase Inhibitory Activity}

The inhibitory activity to $\alpha$-glucosidase of QPs was evaluated according to the published method [46] with some modifications. A mixture of $150 \mu \mathrm{L}$ of QPs solution and $100 \mu \mathrm{L}$ of $0.1 \mathrm{M}$ sodium phosphate buffer $(\mathrm{pH}=6.7)$ containing $\alpha$-glucosidase $(0.1 \mathrm{U} / \mathrm{mL})$ was incubated at $37^{\circ} \mathrm{C}$ for $10 \mathrm{~min}$. Then, $200 \mu \mathrm{L}$ of $1 \mathrm{mM}$ p-nitrophenyl- $\alpha$-D-glucopyranoside (pNPG) solution dissolved in $0.1 \mathrm{M}$ sodium phosphate buffer $(\mathrm{pH}=6.7)$ was added into the mixture after pre-incubation. The reaction mixture was incubated $30 \mathrm{~min}$ at $37^{\circ} \mathrm{C}$. After incubation, the reaction was stopped by adding $1.0 \mathrm{~mL} 0.1 \mathrm{M} \mathrm{Na}_{2} \mathrm{CO}_{3}$, and the absorbance was measured at $405 \mathrm{~nm}$. Acarbose was used as positive control. The inhibitory activity to $\alpha$-glucosidase of QPs was calculated as follows,

$$
\text { inhibition }(\%)=\left(1-\frac{A_{3}-A_{4}}{A_{1}-A_{2}}\right)=\times 100
$$

where $A_{1}$ and $A_{2}$ were the absorbance of control and control blank, $A_{3}$ and $A_{4}$ were the absorbance of sample and sample blank, respectively. Inhibitory activity was expressed as $\mathrm{IC}_{50}$ value.

\subsubsection{Glycemic Index of QPs}

The glycemic index of QPs were determined according to the method of Li et al. [47] by the NutraScan GI 20 equipment (Next Instruments Pty Ltd., New South Wales, Australia). The GI value was calculated as the percentage of available carbohydrates converted to glucose when the incubation time reaches $240 \mathrm{~min}$. 


\subsubsection{Statistical Analysis}

All the results were expressed as the mean \pm standard deviation of triplicate measurements. Statistical analysis was performed using SPSS 19.0 for Windows (SPSS, Inc., Chicago, IL, USA). Statistical significances were carried out by one-way analysis of variance (ANOVA), followed by Duncan's test. Values of $\mathrm{p}<0.05$ were considered as statistically significant.

\section{Conclusions}

In the present study, QPs was prepared by hot water extraction and further fractionated by gradient ethanol precipitation into five fractions of QPE50, QPE60, QPE70, QPE80 and QPE90. The polysaccharide contents were $52.82 \%, 63.69 \%, 67.15 \%, 44.56 \%$ and $41.01 \%$, the protein contents were $11.13 \%, 8.54 \%, 9.50 \%, 7.01 \%$ and $3.32 \%$ and the $\mathrm{Mw}$ were $13,785 \mathrm{Da}, 6489 \mathrm{Da}, 4732 \mathrm{Da}, 3318 \mathrm{Da}$ and $1960 \mathrm{Da}$, respectively. HPLC and IR analysis showed that the five fractions of QPs were composed mainly of glucose. SEM and AFM results showed that QPs samples were mainly in spherical shape, and the intermolecular crosslinking degree and interaction force decreased with the increase in ethanol concentration Among the QPs, QPE90 showed a significantly higher antioxidant and antidiabetic activities than the other QPs. This study confirmed that the antioxidant and antidiabetic activity increase with the decrease of molecular weight of quinoa polysaccharides. It also confirmed that ethanol precipitation is an effective and rapid way to isolate polysaccharides with antioxidant and antidiabetic ability from quinoa polysaccharide. The GI of QPs was significantly correlated with the $\alpha$-glucosidase inhibitory activity using correlation analysis of antidiabetic activity. This indicates that quinoa has the potential to develop into hypoglycemic products.

Author Contributions: L.W., Q.Z. and B.Z. conceived and designed the experiments. M.T. and S.C. performed the experiments. H.L., P.X., P.W. and X.W. analyzed the data, M.T., J.L., H.L., P.X., P.W. and X.W. wrote the initial draft, J.L., L.W., M.Z. and Q.Z. revised the manuscript. All authors have read and agreed to the published version of the manuscript.

Funding: This research was funded by Study on quality standard of quinoa from Dulan based on characteristic indexes (HNYH-2017-80) and Group standard of High Quality Quinoa (4TB202007).

Conflicts of Interest: The authors have declared no conflict of interest.

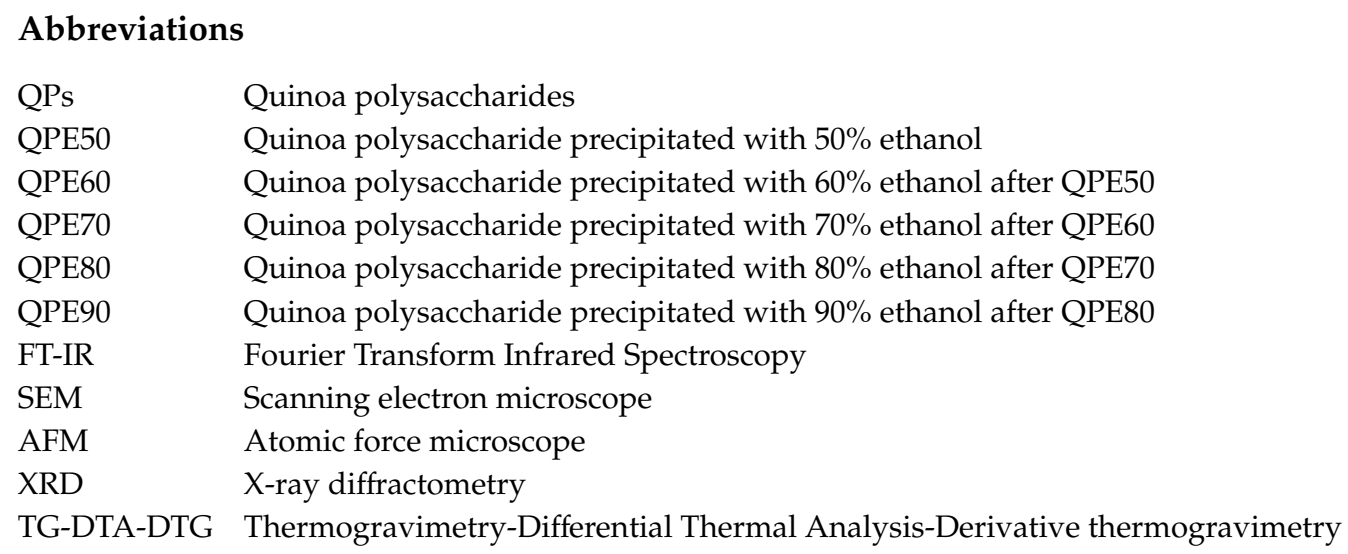

\section{References}

1. Gordillo-Bastidas, E.; Díaz-Rizzolo, D.; Roura, E.; Massanés, T.; Gomis, R. Quinoa (Chenopodium quinoa Willd), from Nutritional Value to Potential Health Benefits: An Integrative Review. J. Nutr. Food Sci. 2016, 6, 1000497.

2. El Hazzam, K.; Hafsa, J.; Sobeh, M.; Mhada, M.; Taourirte, M.; El Kacimi, K.; Yasri, A. An Insight into Saponins from Quinoa (Chenopodium quinoa Willd): A Review. Molecules 2020, 25, 1059. [CrossRef] [PubMed]

3. Bhargava, A.; Shukla, S.; Ohri, D. Chenopodium quinoa-An Indian perspective. Ind. Crops Prod. 2006, 23, 73-87. [CrossRef] 
4. Bhargava, A.; Shukla, S.; Ohri, D. Genetic variability and interrelationship among various morphological and quality traits in quinoa (Chenopodium quinoa Willd.). Field Crop. Res. 2007, 101, 104-116. [CrossRef]

5. Vega-Galvez, A.; Miranda, M.; Vergara, J.; Uribe, E.; Puente, L.; Martinez, E.A. Nutrition facts and functional potential of quinoa (Chenopodium quinoa willd.), an ancient Andean grain: A review. J. Sci. Food Agric. 2010, 90, 2541-2547. [CrossRef]

6. Pereira, E.; Encina-Zelada, C.; Barros, L.; Gonzales-Barron, U.; Cadavez, V.; Ferreira, I.C.F.R. Chemical and nutritional characterization of Chenopodium quinoa Willd (quinoa) grains: A good alternative to nutritious food. Food Chem. 2019, 280, 110-114. [CrossRef]

7. Li, G.; Zhu, F. Quinoa starch: Structure, properties, and applications. Carbohydr. Polym. 2018, 181, 851-861. [CrossRef]

8. Lamothe, L.M.; Srichuwong, S.; Reuhs, B.L.; Hamaker, B.R. Quinoa (Chenopodium quinoa W.) and amaranth (Amaranthus caudatus L.) provide dietary fibres high in pectic substances and xyloglucans. Food Chem. 2015, 167, 490-496. [CrossRef]

9. Lin, M.; Han, P.; Li, Y.; Wang, W.; Lai, D.; Zhou, L. Quinoa Secondary Metabolites and Their Biological Activities or Functions. Molecules 2019, 24, 2512. [CrossRef]

10. Baeva, E.; Bleha, R.; Lavrova, E.; Sushytskyi, L.; Copikova, J.; Jablonsky, I.; Kloucek, P.; Synytsya, A. Polysaccharides from Basidiocarps of Cultivating Mushroom Pleurotus ostreatus: Isolation and Structural Characterization. Molecules 2019, 24, 2740. [CrossRef]

11. Zhang, X.; Zhang, L.; Xu, X. Morphologies and conformation transition of lentinan in aqueous $\mathrm{NaOH}$ solution. Biopolymers 2004, 75, 187-195. [CrossRef] [PubMed]

12. Dunstan, D.E.; Goodall, D.G. Terraced self assembled nano-structures from laminarin. Int. J. Biol. Macromol. 2007, 40, 362-366. [CrossRef] [PubMed]

13. Kashiwagi, Y.; Norisuye, T.; Fujita, H. Triple Helix of Schizophyllum commune Polysaccharide in Dilute Solution. 4. Light Scattering and Viscosity in Dilute Aqueous Sodium Hydroxide. Macromolecules 1981, 14, 1220-1225. [CrossRef]

14. Wang, J.; Xu, X.; Zheng, H.; Li, J.; Deng, C.; Xu, Z.; Chen, J. Structural Characterization, Chain Conformation, and Morphology of a $\beta-(1 \rightarrow 3)-D-G l u c a n$ Isolated from the Fruiting Body of Dictyophora indusiata. J. Agric. Food Chem. 2009, 57, 5918-5924. [CrossRef]

15. Sun, Y.; Hou, S.; Song, S.; Zhang, B.; Ai, C.; Chen, X.; Liu, N. Impact of acidic, water and alkaline extraction on structural features, antioxidant activities of Laminaria japonica polysaccharides. Int. J. Biol. Macromol. 2018, 112, 985-995. [CrossRef]

16. Zhang, J.; Wen, C.; Gu, J.; Ji, C.; Duan, Y.; Zhang, H. Effects of subcritical water extractionmicroenvironment on the structure and biological activities of polysaccharides from Lentinus edodes. Int. J. Biol. Macromol. 2019, 123, 1002-1011. [CrossRef]

17. Wang, S.; Zhao, L.; Li, Q.; Liu, C.; Han, J.; Zhu, L.; Zhu, D.; He, Y.; Liu, H. Rheological properties and chain conformation of soy hull water-soluble polysaccharide fractions obtained by gradient alcohol precipitation. Food Hydrocoll. 2019, 91, 34-39. [CrossRef]

18. Jiang, Y.; Yu, J.; Li, Y.; Wang, L.; Hu, L.; Zhang, L.; Zhou, Y. Extraction and antioxidant activities of polysaccharides from roots of Arctium lappa L. Int. J. Biol. Macromol. 2019, 123, 531-538. [CrossRef]

19. Fan, S.; Li, J.; Bai, B. Purification, structural elucidation and in vivo immunity-enhancing activity of polysaccharides from quinoa (Chenopodium quinoa Willd.) seeds. Biosci. Biotechnol. Biochem. 2019, 83, 2334-2344. [CrossRef]

20. Xu, S.; Lin, Y.; Huang, J.; Li, Z.; Xu, X.; Zhang, L. Construction of high strength hollow fibers by self-assembly of a stiff polysaccharide with short branches in water. J. Mater. Chem. A 2013, 1, 4198. [CrossRef]

21. Wang, L.; Liu, F.; Wang, A.; Yu, Z.; Xu, Y.; Yang, Y. Purification, characterization and bioactivity determination of a novel polysaccharide from pumpkin (Cucurbita moschata) seeds. Food Hydrocoll. 2017, 66, 357-364. [CrossRef]

22. Xin, Y.; Chen, F.; Lai, S.; Yang, H. Influence of chitosan-based coatings on the physicochemical properties and pectin nanostructure of Chinese cherry. Postharvest Biol. Technol. 2017, 133, 64-71. [CrossRef]

23. Chen, L.; Zhou, Y.; He, Z.; Liu, Q.; Lai, S.; Yang, H. Effect of exogenous ATP on the postharvest properties and pectin degradation of mung bean sprouts (Vigna radiata). Food Chem. 2018, 251, 9-17. [CrossRef] [PubMed] 
24. Zhang, L.; Zhao, S.; Lai, S.; Chen, F.; Yang, H. Combined effects of ultrasound and calcium on the chelate-soluble pectin and quality of strawberries during storage. Carbohydr. Polym. 2018, 200, 427-435. [CrossRef] [PubMed]

25. Wang, Y.; Peng, Y.; Wei, X.; Yang, Z.; Xiao, J.; Jin, Z. Sulfation of tea polysaccharides: Synthesis, characterization and hypoglycemic activity. Int. J. Biol. Macromol. 2010, 46, 270-274. [CrossRef]

26. Zhang, Y.; Li, S.; Wang, X.; Zhang, L.; Cheung, P.C.K. Advances in lentinan: Isolation, structure, chain conformation and bioactivities. Food Hydrocoll. 2011, 25, 196-206. [CrossRef]

27. Qian, J.; Chen, W.; Zhang, W.; Zhang, H. Adulteration identification of some fungal polysaccharides with SEM, XRD, IR and optical rotation: A primary approach. Carbohydr. Polym. 2009, 78, 620-625. [CrossRef]

28. Wang, K.; Wang, J.; Li, Q.; Zhang, Q.; You, R.; Cheng, Y.; Luo, L.; Zhang, Y. Structural differences and conformational characterization of five bioactive polysaccharides from Lentinus edodes. Food Res. Int. 2014, 62, 223-232. [CrossRef]

29. Kong, L.; Yu, L.; Feng, T.; Yin, X.; Liu, T.; Dong, L. Physicochemical characterization of the polysaccharide from Bletilla striata: Effect of drying method. Carbohydr. Polym. 2015, 125, 1-8. [CrossRef]

30. Jeddou, K.B.; Chaari, F.; Maktouf, S.; Nouri-Ellouz, O.; Helbert, C.B.; Ghorbel, R.E. Structural, functional, and antioxidant properties of water-soluble polysaccharides from potatoes peels. Food Chem. 2016, 205, 97-105. [CrossRef]

31. Patel, M.K.; Tanna, B.; Mishra, A.; Jha, B. Physicochemical characterization, antioxidant and anti-proliferative activities of a polysaccharide extracted from psyllium (P. ovata) leaves. Int. J. Biol. Macromol. 2018, 118, 976-987. [CrossRef] [PubMed]

32. Wang, Y.; Yang, Z.; Wei, X. Sugar compositions, $\alpha$-glucosidase inhibitory and amylase inhibitory activities of polysaccharides from leaves and flowers of Camellia sinensis obtained by different extraction methods. Int. J. Biol. Macromol. 2010, 47, 534-539. [CrossRef] [PubMed]

33. Sun, Q.; Spiegelman, D.; Dam, R.M.V.; Holmes, M.D.; Malik, V.S.; Willett, W.C.; Hu, F.B. White Rice, Brown Rice, and Risk of Type 2 Diabetes in US Men and Women. Arch. Intern. Med. 2010, 170, 961. [CrossRef] [PubMed]

34. Brand-Miller, J.; Hayne, S.; Petocz, P.; Colagiuri, S. Low-Glycemic Index Diets in the Management of Diabetes: A meta-analysis of randomized controlled trials. Diabetes Care 2003, 26, 2261-2267. [CrossRef]

35. Agama-Acevedo, E.; Islas-Hernández, J.J.; Pacheco-Vargas, G.; Osorio-Díaz, P.; Bello-Pérez, L.A. Starch digestibility and glycemic index of cookies partially substituted with unripe banana flour. LWT-Food Sci. Technol. 2012, 46, 177-182. [CrossRef]

36. Bhat, M.; Zinjarde, S.S.; Bhargava, S.Y.; Kumar, A.R.; Joshi, B.N. Antidiabetic Indian Plants: A Good Source of Potent Amylase Inhibitors. Evid. -Based Complementary Altern. Med. 2011, 2011, 810207. [CrossRef]

37. Dubois, M.; Gilles, K.A.; Hamilton, J.K.; Rebers, P.A.; Smith, F. Colorimetric Method for Determination of Sugars and Related Substances. Anal. Chem. 1956, 28, 350-356. [CrossRef]

38. Bradford, M.M. A Rapid and Sensitive Method for the Quantitation of Microgram Quantities of Protein Utilizing the Principle of Protein-Dye Binding. Anal. Biochem. 1976, 72, 248-254. [CrossRef]

39. Bitter, T.; Muir, H.M. A Modified Uronic Acid Carbazole Reaction. Anal. Chem. 1962, 4, 330-334. [CrossRef]

40. Zhu, J.; Chen, Z.; Chen, L.; Yu, C.; Wang, H.; Wei, X.; Wang, Y. Comparison and structural characterization of polysaccharides from natural and artificial Se-enriched green tea. Int. J. Biol. Macromol. 2019, 130, 388-398. [CrossRef]

41. Dai, J.; Wu, Y.; Chen, S.-W.; Zhu, S.; Yin, H.-P.; Wang, M.; Tang, J. Sugar compositional determination of polysaccharides from Dunaliella salina by modified RP-HPLC method of precolumn derivatization with 1-phenyl-3-methyl-5-pyrazolone. Carbohydr. Polym. 2010, 82, 629-635. [CrossRef]

42. Wang, X.; Zhu, Z.; Zhao, L.; Sun, H.; Meng, M.; Zhang, J.; Zhang, Y. Structural characterization and inhibition on $\alpha$ - D -glucosidase activity of non-starch polysaccharides from Fagopyrum tartaricum. Carbohydr. Polym. 2016, 153, 679-685. [CrossRef] [PubMed]

43. Zhou, X.; Yan, L.; Yin, P.; Shi, L.; Zhang, J.; Liu, Y.; Ma, C. Structural characterisation and antioxidant activity evaluation of phenolic compounds from cold-pressed Perilla frutescens var. arguta seed flour. Food Chem. 2014, 164, 150-157. [CrossRef]

44. Re, R.; Pellegrini, N.; Proteggente, A.; Pannala, A.; Yang, M.; Rice-Evans, C. Antioxidant activity applying an improved ABTS radical cation decolorization assay. Free Radical Biol. Med. 1999, 26, 1231-1237. [CrossRef] 
45. Xiao, Z.; Storms, R.; Tsang, A. A quantitative starch-iodine method for measuring alpha-amylase and glucoamylase activities. Anal. Biochem. 2006, 351, 146-148. [CrossRef] [PubMed]

46. Kim, J.-S.; Hyun, T.K.; Kim, M.-J. The inhibitory effects of ethanol extracts from sorghum, foxtail millet and proso millet on $\alpha$-glucosidase and $\alpha$-amylase activities. Food Chem. 2011, 124, 1647-1651. [CrossRef]

47. Li, H.; Li, J.; Xiao, Y.; Cui, B.; Fang, Y.; Guo, L. In vitro digestibility of rice starch granules modified by $\beta$-amylase, transglucosidase and pullulanase. Int. J. Biol. Macromol. 2019, 136, 1228-1236. [CrossRef]

Sample Availability: Not available.

(C) 2020 by the authors. Licensee MDPI, Basel, Switzerland. This article is an open access article distributed under the terms and conditions of the Creative Commons Attribution (CC BY) license (http://creativecommons.org/licenses/by/4.0/). 